\title{
DOSES E FORMAS DE APLICAÇÃO DE NITROGÊNIO NO DESENVOLVIMENTÓ E PRODUÇÃO DA CULTURA DO TRIGO
}

\author{
Nitrogen application methods and doses in the development and yield of wheat
}

\author{
Marcelo Curitiba Espindula1, Valterley Soares Rocha², Moacil Alves de Souza², \\ José Antônio Saraiva Grossi², Leandro Torres de Souza ${ }^{3}$
}

\begin{abstract}
RESUMO
Objetivou-se avaliar o efeito de doses e formas de aplicação de nitrogênio sobre o desempenho e produção de duas cultivares de

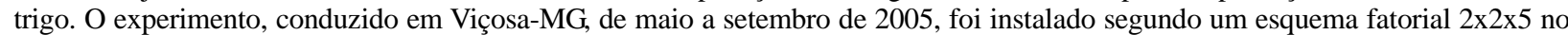
delineamento de blocos casualizados, com quatro repetições. Os tratamentos avaliados consistiram da combinação das cultivares de trigo, BRS 210 e Pioneiro, duas formas de aplicação de adubo nitrogenado (dose total aplicada por ocasião da semeadura ou $20 \mathrm{~kg} \mathrm{ha}^{-1}$ na semeadura e o restante em cobertura no início da fase de perfilhamento) e cinco doses de nitrogênio $\left(40,60,80,100\right.$ e $\left.120 \mathrm{~kg}^{-1}\right)$ tendo como fonte o sulfato de amônio. A cultivar Pioneiro apresentou maior potencial produtivo que a cultivar BRS 210, mas foi menos resistente ao acamamento. O parcelamento da adubação nitrogenada proporcionou maior acamamento e não trouxe benefícios à produtividade dos grãos. As doses de $\mathrm{N}$ promoveram resposta quadrática da produtividade dos grãos, com ponto de máxima estimado na dose de $96,8 \mathrm{~kg} \mathrm{ha}^{-1}$ e, aumento linear do acamamento de plantas da cultivar Pioneiro.
\end{abstract}

Termos para indexação: Triticum aestivum, adubação nitrogenada, acamamento, produtividade.

\section{ABSTRACT}

The objective of this work was to evaluate the effect of doses and methods of nitrogen application on the development and yield of two wheat cultivars. The experiment was conducted in Viçosa-MG, from May to September 2005, and it was arranged in a $2 \times 2 \times 5$ factorial, randomized block design with four repetitions. The treatments consisted of the combination of the two wheat cultivars, BRS 210 and Pioneiro, two nitrogen application methods (total dose applied at seed sowing or $20 \mathrm{~kg} \mathrm{ha}^{-1}$ at sowing and the remaining as topdressing in the beginning of tillage) and five $\mathrm{N}$ doses $\left(40,60,80,100\right.$ and $\left.120 \mathrm{~kg} \mathrm{ha}^{-1}\right)$ with ammonium sulfate as $\mathrm{N}$ source. Cultivar Pioneiro showed higher yield potential than cultivar BRS 210, but it was less resistance to lodging. Splitting nitrogen fertilization increased lodging and brought no benefit to grain yield. Grain yield response to $\mathrm{N}$ doses was quadratic, reaching maximum at $96.8 \mathrm{~kg} \mathrm{ha}^{-1}$, and linear increase in lodging of cultivar Pioneiro plants.

Index terms: Triticum aestivum, nitrogen fertilization, lodging, yield.

(Recebido em 13 de janeiro de 2009 e aprovado em 30 de outubro de 2009)

\section{INTRODUÇÃo}

O nitrogênio é, provavelmente, o segundo maior fator limitante da produção agrícola, perdendo apenas para a deficiência hídrica (Date, 2000; Graham \& Vance, 2000). É constituinte de proteínas, enzimas, coenzimas, ácidos nucléicos, fitocromos e da clorofila, além de afetar as taxas de iniciação e expansão foliar, o tamanho final e a intensidade de senescência das folhas (Schröder et al., 2000).

A variabilidade das condições edafoclimáticas e de manejo cultural (Simili et al., 2008), associada aos múltiplos processos que interferem na complexa dinâmica do N no solo (lixiviação, volatilização, imobilização-mobilização, nitrificação, desnitrificação e mineralização) e na suas relações com a planta, podem ocasionar grandes modificações na disponibilidade e na necessidade desse nutriente, durante a ontogenia da planta (Rambo et al., 2004).

As Poaceas, como o trigo, apresentam em sua constituição cerca de $2,9 \%$ de $\mathrm{N}$ na planta inteira e $2 \%$ nos grãos (Cantarella, 2007) e, por não se beneficiarem da fixação biológica de nitrogênio, na mesma proporção que outras plantas como as Fabaceae, precisam obter praticamente todo o $\mathrm{N}$ do solo e dos fertilizantes. Por isso, é necessário estabelecer a relação entre o $\mathrm{N}$ disponível no solo e o aplicado, via fertilizantes, com o rendimento de grãos (Pöttker \& Roman, 1998).

Diversos trabalhos foram realizados acerca da época correta da aplicação de $\mathrm{N}$ para adequá-la à absorção e utilização de $\mathrm{N}$, durante o ciclo da cultura do trigo (Vieira et

1Universidade Federal de Viçosa/UFV - Departamento de Fitotecnia - Avenida Peter Henry Holfs - s/n - 36570-000 - Viçosa, MG - curitibaespindula@yahoo.com.br
2Universidade Federal de Viçosa/UFV - Departamento de Fitotecnia - Viçosa, MG ${ }^{3}$ Universidade Federal de Viçosa/UFV - Departamento de Fisiologia Vegetal - Viçosa, MG 
al., 1995; Coelho et al., 1998; Bredemeier \& Mundstock, 2001; Sangoi et al., 2007). Alguns desses estudos indicam que o parcelamento da adubação nitrogenada resulta em maior recuperação do nutriente pela cultura e maior produtividade, quando comparados com a aplicação única (Sangoi et al., 2007, Wamser \& Mundstock, 2007, Megda et al., 2009). Por outro lado, existem resultados que contradizem os efeitos vantajosos do parcelamento (Coelho et al., 1998). Por isso, a proporção do parcelamento deve considerar fatores como o ambiente, o manejo, e a cultivar de maneira a se obter recomendações específicas e não generalizadas.

A dose ideal do nitrogênio a ser aplicada na cultura também depende de diversos fatores. Trindade et al. (2006) encontraram aumentos na produtividade de grãos em duas cultivares de trigo Embrapa 22 e Embrapa 42, quando aplicaram 0, 50, 100, 150 e $200 \mathrm{~kg} \mathrm{ha}^{-1}$ de N. Entretanto, Braz et al. (2006) encontraram aumentos lineares, respostas quadráticas ou ausência de efeitos significativos no rendimento de grãos para a cultivar Embrapa 42, tratadas com $0,30,60$ e $120 \mathrm{~kg} \mathrm{ha}^{-1}$ de $\mathrm{N}$ sendo essa resposta variável com o tipo de cultura antecessora. Ou seja, a resposta à doses de $\mathrm{N}$, pode se comportar de maneiras completamente distintas, quando se varia as condições de cultivo.

Para as condições do Brasil Central, que inclui Minas Gerais, a adubação nitrogenada em trigo é realizada em duas etapas: por ocasião da semeadura e, no início do estádio de perfilhamento, antes do início do processo de diferenciação floral (cerca de 15 dias após a emergência). As cultivares BRS 210 e Pioneiro, utilizadas neste estudo, são comerciais e apresentam, respectivamente, moderada resistência e moderadamente susceptibilidade ao acamamento de plantas. Para a cultivar BRS 210, a recomendação de adubação nitrogenada é de $20 \mathrm{~kg} \mathrm{ha}^{-1}$ de $\mathrm{N}$, por ocasião da semeadura e até $100 \mathrm{~kg}$ em cobertura, enquanto para a cultivar Pioneiro recomenda-se aplicar $20 \mathrm{~kg} \mathrm{ha}^{-1}$ de $\mathrm{N}$ na semeadura e até $80 \mathrm{~kg}$ em cobertura (Empresa Brasileira de Pesquisa Agropecuária - Embrapa, 2005). Essa recomendação é ampla, mas, como a dinâmica de aplicação e utilização desse nutriente está em função das especificidades das condições de cultivo, a adoção dessas recomendações deve ser feita com precaução.

Objetivou-se com esta pesquisa avaliar o efeito de doses e formas de aplicação de nitrogênio no desenvolvimento e produção de duas cultivares de trigo.

\section{MATERIAL E MÉTODOS}

O experimento foi conduzido na Estação Experimental Professor Diogo Alves de Mello, da Universidade Federal de Viçosa, Viçosa-MG (2045' S e 42 ${ }^{\circ} 51^{\prime}$ W e altitude de $650 \mathrm{~m}$ ), no período de maio a setembro de 2005.
A área utilizada para implantação do experimento foi cultivada nos últimos anos com soja (verão) e trigo (inverno). O solo da área é classificado como Argissolo VermelhoAmarelo (Fase Terraço). A análise química do solo, determinada na camada de 0 a $20 \mathrm{~cm}$, apresentou as seguintes características: $\mathrm{pH}\left(\mathrm{em} \mathrm{H}_{2} \mathrm{O}\right)=5,60 ; \mathrm{P}=11,47 \mathrm{mg} \mathrm{dm}^{-3} ; \mathrm{K}^{+}=$ $115 \mathrm{mg} \mathrm{dm}{ }^{-3} ; \mathrm{Ca}^{2+}=1,89 \mathrm{cmolc} \mathrm{dm}^{-3} ; \mathrm{Mg}^{2+}=0,28 \mathrm{cmolc} \mathrm{dm}^{-3}$; $\mathrm{Al}^{3+}=0,00 \mathrm{cmol}_{c} \mathrm{dm}^{-3} ; \mathrm{H}+\mathrm{Al}=3,11 \mathrm{cmol} \mathrm{dm}_{\mathrm{c}}^{-3}$; saturação de base $(\mathrm{V})=44 \%$ e matéria orgânica $(\mathrm{MO})=1,5 \mathrm{dag} \mathrm{kg}^{-1}$.

$\mathrm{O}$ experimento foi instalado no delineamento de blocos casualizados com quatro repetições, seguindo um esquema fatorial $2 \times 2 \times 5$ constituído de duas cultivares, duas formas de aplicação de $\mathrm{N}$ e de cinco doses do mesmo. As duas cultivares de trigo (Triticum aestivum L.) foram a BRS 210 e a Pioneiro. As duas formas de aplicação de adubo nitrogenado foram: dose total aplicada por ocasião da semeadura ou $20 \mathrm{~kg} \mathrm{ha}^{-1}$ na semeadura e o restante em cobertura no início da fase de perfilhamento (14 dias após a emergência). As cinco doses de $\mathrm{N}$ utilizadas foram 40, 60, 80,100 e $120 \mathrm{~kg} \mathrm{ha}^{-1}(25,76 ; 38,64 ; 51,54 ; 64,4$ e 77,28 gramas de $\mathrm{N}$ por parcela respectivamente). Cada parcela foi formada por sete linhas com $5 \mathrm{~m}$ de comprimento, espaçadas entre si em $0,18 \mathrm{~m}$. A área útil da parcela, 2,21 $\mathrm{m}^{2}$, foi constituída por três linhas centrais, sendo eliminado meio $0,5 \mathrm{~m}$ em ambas as extremidades das linhas.

O preparo do solo foi realizado por meio de uma aração e duas gradagens. Na semeadura utilizou-se a dose de $250 \mathrm{~kg} \mathrm{ha}^{-1}$ do formulado comercial 08-28-16 (20 kg ha-1 de $\mathrm{N}$ ), sendo que para a complementação da dose total de $\mathrm{N}$ aplicada na semeadura (aplicação em cobertura e posterior incorporação com semeadora no momento da semeadura), bem como para cobertura, realizada 15 dias após a emergência, utilizou-se como fonte de N, o sulfato de amônio. $\mathrm{O}$ enxofre contido no sulfato de amônio, mesmo na menor dose (46 $\mathrm{kg} \mathrm{ha}^{-1} \mathrm{de} \mathrm{S}$ ), está acima das necessidades dos cereais, 15 a $30 \mathrm{~kg} \mathrm{ha}^{-1}$, portanto, os resultados obtidos referem-se a efeitos do $\mathrm{N}$.

Foi avaliado o acamamento de plantas, pela medição direta da área acamada e transformação para porcentagem; a altura de plantas medindo-se do coleto até o ápice da espiga e excluindo-se as aristas; o diâmetro do pedúnculo, a cinco $\mathrm{cm}$ de altura a partir do último nó; a massa de mil grãos, determinada a partir de oito repetições de 100 grãos, e a massa do hectolitro, utilizando balança apropriada e o número de espigas por $\mathrm{m}^{2}$, determinado pela contagem direta, em três segmentos de $1 \mathrm{~m}$ de fileira, tomados ao acaso na parcela útil. $\mathrm{O}$ número de grãos por espiga, a massa seca da parte aérea e o índice de colheita (razão entre a produtividade de grãos e a massa seca da parte aérea), foram determinados em 100 plantas colhidas em 
sequência na fileira central da parcela. A produtividade de grãos, com umidade corrigida para $13 \%$, foi determinada a partir da colheita dos grãos da área útil das parcelas e transformação para $\mathrm{kg} \mathrm{ha}^{-1}$.

Os dados foram submetidos à análise de variância e, sendo detectadas diferenças, aplicou-se o teste de Tukey, a 5\% de probabilidade, para as comparações entre médias e, para os efeitos de doses, aplicaram-se análises de regressão, sendo os modelos matemáticos escolhidos segundo as equações com melhores ajustes, confirmados pelos maiores valores dos coeficientes de determinação $\left(\mathrm{R}^{2}\right)$ e pela significância dos coeficientes de regressão $\left(\beta_{\mathrm{i}}\right)$ e do teste $\mathrm{F}$ da regressão, ambos a até $5 \%$ de probabilidade. As significâncias dos coeficientes de regressão $\left(\beta_{\mathrm{i}}\right)$ estão apresentadas nas equações por $* \mathrm{e}^{* *}$, significativos a $5 \mathrm{e}$ $1 \%$ respectivamente.

\section{RESULTADOS E DISCUSSÃO}

A cultivar BRS 210 não apresentou acamamento em nenhuma das formas de aplicação e doses de nitrogênio. Por outro lado, para a cultivar Pioneiro, o parcelamento promoveu maior acamamento que a aplicação em dose única. A cultivar Pioneiro também apresentou acamamento significativamente superior ao da cultivar BRS 210 na aplicação parcelada e nas doses de 100 e $120 \mathrm{~kg} \mathrm{ha}^{-1}$ de N (Tabela 1).

A ausência de acamamento da cultivar BRS 210 confirma a indicação de moderada resistência dessa cultivar ao fenômeno. Esses resultados corroboram os

Tabela 1 - Valores médios do acamamento de plantas (\%) de duas cultivares de trigo, em resposta a doses e formas de aplicação de nitrogênio.

\begin{tabular}{lcc}
\hline Forma de aplicação $^{1}$ & \multicolumn{2}{c}{ Cultivar } \\
\cline { 2 - 3 } & BRS 210 & Pioneiro \\
\hline Única & $0,00 \mathrm{Aa}$ & $3,84 \mathrm{Ab}$ \\
Parcelada & $0,00 \mathrm{Ba}$ & $18,91 \mathrm{Aa}$ \\
\hline Dose de N $\left(\mathrm{kg} \mathrm{ha}^{-1}\right)^{2}$ & & \\
\hline 40 & $0,00 \mathrm{~A}$ & $0,00 \mathrm{~A}$ \\
60 & $0,00 \mathrm{~A}$ & $2,81 \mathrm{~A}$ \\
80 & $0,00 \mathrm{~A}$ & $4,48 \mathrm{~A}$ \\
100 & $0,00 \mathrm{~B}$ & $22,83 \mathrm{~A}$ \\
120 & $0,00 \mathrm{~B}$ & $26,87 \mathrm{~A}$ \\
\hline
\end{tabular}

${ }^{1}$ Desdobramento da interação cultivar $\mathrm{x}$ formas de aplicação. ${ }^{2}$ Desdobramento da interação cultivar x doses. Médias seguidas pela mesma letra maiúscula na linha e minúscula na coluna, não diferem entre si, a $5 \%$ de probabilidade pelo teste de Tukey. encontrados para quatro cultivares de trigo em São Paulo (Teixeira Filho et al., 2007) e para oito cultivares no Paraná (Zagonel \& Fernandes, 2007). Já os níveis de acamamento da cultivar Pioneiro, nas doses de 100 e $120 \mathrm{~kg} \mathrm{ha}^{-1}$ de N, indicam susceptibilidade dessa cultivar ao aumento das doses de N. A susceptibilidade ao acamamento pode estar relacionada ao excessivo crescimento vegetativo, provocado por desbalanço nutricional, baixa resistência do colmo, massa das espigas, fatores climáticos desfavoráveis, entre outros. Acredita-se que, neste estudo, o acamamento tenha ocorrido pela moderada resistência do colmo, combinada com a massa das espigas, pois tal cultivar apresentou considerável rendimento de grãos em resposta às doses de $\mathrm{N}$ e, ainda, pelas precipitações pluviais intensas, no final do enchimento dos grãos.

O maior acamamento da cultivar Pioneiro, observado na aplicação parcelada, não corrobora os resultados obtidos por Coelho et al. (1998), que trabalhando com a cultivar de trigo EMBRAPA - 22, encontraram menor acamamento quando se parcelou a adubação de cobertura. No entanto, plantas que recebem doses elevadas de nitrogênio em cobertura podem promover enchimento de grãos excessivo e incompatível com a estrutura caulinar formada durante $o$ desenvolvimento inicial da planta, o que poderia explicar os resultados deste estudo.

As características altura de plantas, diâmetro do pedúnculo, número de grãos por espiga, produtividade e índice de colheita da cultivar Pioneiro foi maior que os da cultivar BRS 210, enquanto que a massa do hectolitro e o número de espigas por metro quadrado da BRS 210 foram maiores que os da Pioneiro. Para as formas de aplicação, somente as características diâmetro do pedúnculo e número de grãos por espiga foram significativamente diferentes, tendo a aplicação em forma única apresentado maior valor (Tabela 2).

A altura de plantas e o diâmetro de pedúnculo são particularidades de cada cultivar e isso explica as diferenças encontradas. O maior diâmetro do pedúnculo, aplicação em dose única, pode estar relacionado com a maior disponibilidade de N, no início da formação dessa estrutura. Zagonel \& Fernandes (2007) encontraram respostas variadas das cultivares ao aumento da dose de $\mathrm{N}$ para essa característica, o que sugere também a influência de fatores genéticos.

O maior número de grãos por espiga, aplicação em dose única, são semelhantes aos relatados por Sangoi et al. (2007). Acredita-se que a melhor condição nutricional, resultante da maior disponibilidade de $\mathrm{N}$ para as plantas, no momento da diferenciação da gema vegetativa em reprodutiva, seja responsável pela diferença. 
Tabela 2 - Valores médios de características avaliadas em duas cultivares de trigo, em resposta a formas de aplicação de nitrogênio. Viçosa-MG, 2005.

\begin{tabular}{lccccccc}
\hline \multirow{2}{*}{ Cultivar $^{1}$} & \multicolumn{7}{c}{ Característica } \\
\cline { 2 - 8 } & $\begin{array}{c}\text { Altura de } \\
\text { plantas }\end{array}$ & $\begin{array}{c}\text { Diâmetro do } \\
\text { pedúnculo }\end{array}$ & $\begin{array}{c}\text { Massa do } \\
\text { hectolitro }\end{array}$ & $\begin{array}{c}\mathrm{N}^{\mathbf{0}} \text { de grãos } \\
\text { espiga }^{-1}\end{array}$ & $\begin{array}{c}\mathrm{N}^{\mathrm{o}} \text { de espigas } \\
\mathrm{m}^{-2}\end{array}$ & $\begin{array}{c}\text { Produtividade } \\
\text { dos grãos }\end{array}$ & $\begin{array}{c}\text { Índice de } \\
\text { colheita }\end{array}$ \\
\hline BRS 210 & $79,99 \mathrm{~b}$ & $29,45 \mathrm{~b}$ & $76,20 \mathrm{a}$ & $27,77 \mathrm{~b}$ & $476,64 \mathrm{a}$ & $4673 \mathrm{~b}$ & $0,452 \mathrm{~b}$ \\
Pioneiro & $93,92 \mathrm{a}$ & $30,15 \mathrm{a}$ & $74,70 \mathrm{~b}$ & $36,31 \mathrm{a}$ & $404,03 \mathrm{~b}$ & $4985 \mathrm{a}$ & $0,464 \mathrm{a}$ \\
\hline Aplicação $^{2}$ & & & & & & & \\
\hline Única & $86,81 \mathrm{a}$ & $30,12 \mathrm{a}$ & $75,57 \mathrm{a}$ & $32,69 \mathrm{a}$ & $443,36 \mathrm{a}$ & $4890 \mathrm{a}$ & $0,459 \mathrm{a}$ \\
Parcelada & $87,10 \mathrm{a}$ & $29,48 \mathrm{~b}$ & $75,33 \mathrm{a}$ & $31,39 \mathrm{~b}$ & $437,30 \mathrm{a}$ & $4768 \mathrm{a}$ & $0,457 \mathrm{a}$ \\
\hline
\end{tabular}

${ }^{1}$ Efeito do fator cultivar e ${ }^{2}$ Efeito do fator formas de aplicação. Não houve interações significativas para essas características. Médias seguidas pela mesma letra minúscula na coluna, não diferem significativamente entre si, a 5\% de probabilidade pelo teste F.

O maior número de espigas por $\mathrm{m}^{2}$ da cultivar BRS 210 pode ser devido às características dessa cultivar que apresentam folhas menores, mais eretas e menos prostradas o que pode ter proporcionado menor sombreamento e, consequentemente, menor índice de abortamento dos perfilhos. Resultados semelhantes podem ser conseguidos com a aplicação de redutores de crescimento (Alvarez et al., 2007).

Para a massa do hectolitro, os resultados sugerem melhor enchimento de grãos da cultivar BRS 210. No entanto, o maior número de grãos por espigas da cultivar Pioneiro foi, provavelmente, a característica que mais influenciou as diferenças de produtividade entre as cultivares, uma vez que a massa do hectolitro e o número de espiga por $\mathrm{m}^{2}$ da cultivar BRS 210 foram superiores as da cultivar Pioneiro. Esses resultados confirmam a indicação de que o número de grãos por espiga constitui um dos componentes de produção que mais se associa com a produção de grãos (Sangoi et al., 2007).

As produtividades dos grãos, de ambas as cultivares são similares às relatadas na literatura para outras cultivares e condições (Fontes et al., 2000; Coelho et al., 2001; Trindade et al., 2006). Porém, a diferença observada entre as mesmas, evidencia o maior potencial produtivo da cultivar Pioneiro. Quanto ao índice de colheita, a diferença sugere maior eficiência da cultivar Pioneiro para produção de grãos em relação à produção de partes vegetativas, $o$ que é vantajoso tendo em vista que, na cultura do trigo, o produto colhido e comercializado é o grão.

A ausência de diferenças significativas entre as formas de aplicação para as características altura de plantas, massa do hectolitro, número de espigas por $\mathrm{m}^{2}$, índice de colheita $\mathrm{e}$, principalmente, produtividade sugere não ser vantajosa a aplicação parcelada de $\mathrm{N}$, para as condições estudadas. Essa resposta ocorre devido ao curto período entre a semeadura e a aplicação em cobertura (19 dias), uma vez que, nas condições do Brasil central, as temperaturas elevadas adiantam o ciclo da cultura.

Para a característica massa de mil grãos, a cultivar BRS 210 superou a Pioneiro em ambas as formas de aplicação do fertilizante nitrogenado e a aplicação em dose única promoveu maior massa de grãos na cultivar Pioneiro (Tabela 3).

Tabela 3 - Massa de mil grãos (g) de duas cultivares de trigo, em resposta a formas de aplicação de nitrogênio. Viçosa-MG, 2005.

\begin{tabular}{lll}
\hline Forma de aplicação & \multicolumn{2}{c}{ Cultivar } \\
\cline { 2 - 3 } & BRS 210 & Pioneiro \\
\hline Única & $38,12 \mathrm{Aa}$ & $36,70 \mathrm{Ba}$ \\
Parcelada & $38,40 \mathrm{Aa}$ & $35,46 \mathrm{Bb}$ \\
\hline
\end{tabular}

Médias seguidas pela mesma letra maiúscula na linha e minúscula na coluna, não diferem significativamente entre si, a $5 \%$ de probabilidade pelo teste de Tukey.

As diferenças entre cultivares, para massa de mil grãos, podem ser atribuídas à fatores genéticos. Já a menor massa de grãos da cultivar Pioneiro, quando se parcelou a adubação, relaciona-se com a ocorrência de maior acamamento nessa forma de aplicação. Isso porque, com as plantas acamadas, o enchimento de grãos fica prejudicado, além de que, quando o acamamento ocorre no estádio de maturação fisiológica dos grãos, esses iniciam o processo 
de germinação na espiga, aumentando a respiração e diminuindo sua massa (Zagonel \& Fernandes, 2007).

As doses de $\mathrm{N}$ influenciaram, de forma não linear (modelo sigmóide), o acamamento das plantas da cultivar Pioneiro, promoveram acréscimos lineares nas características altura de plantas e diâmetro do pedúnculo e decréscimo linear na massa de mil grãos (Figura 1).

$\mathrm{O}$ aumento linear da altura de plantas, em função das doses de N, é semelhante aos encontrados para trigo (Zagonel \& Fernandes, 2007) e painço (Panicum miliaceum L.) (Soratto et al., 2007). Esses resultados são plausíveis, pois o aumento no suprimento de $\mathrm{N}$ estimula a elongação do caule em cereais. No entanto, esse incremento não é favorável, uma vez que o maior comprimento das plantas vem, geralmente, acompanhado de maior predisposição ao acamamento. Por outro lado, o aumento do diâmetro do caule, em função das doses de $\mathrm{N}$, pode ser positivo, visto que, no colmo ocorre armazenamento de assimilados que podem ser translocados, durante o enchimento dos grãos.

Para a massa de mil grãos, resultado semelhante foi relatado para arroz (Buzetti et al., 2006). Esse comportamento é esperado para algumas cultivares devido à elevada produção de massa vegetal promovida pelas doses crescentes de N (Figura 2), causando autossombreamento e comprometendo a eficiência fotossintética das plantas. Além disso, existe efeito compensatório entre os componentes de produção, ou seja, o aumento de uma

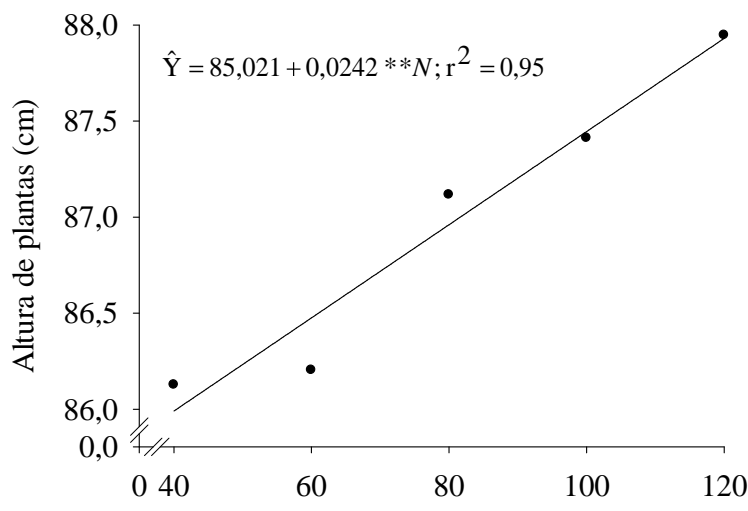

(B)

Dose de nitrogênio $\left(\mathrm{kg} \mathrm{ha}^{-1}\right)$

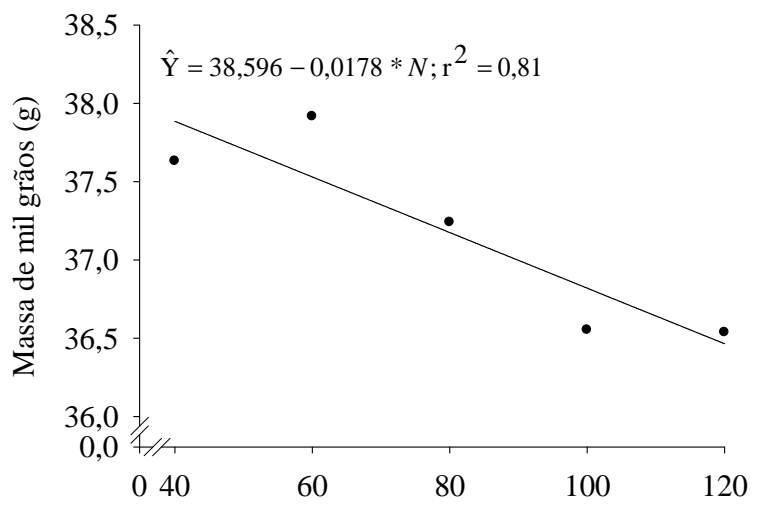

(D)

Dose de nitrogênio $\left(\mathrm{kg} \mathrm{ha}^{-1}\right)$

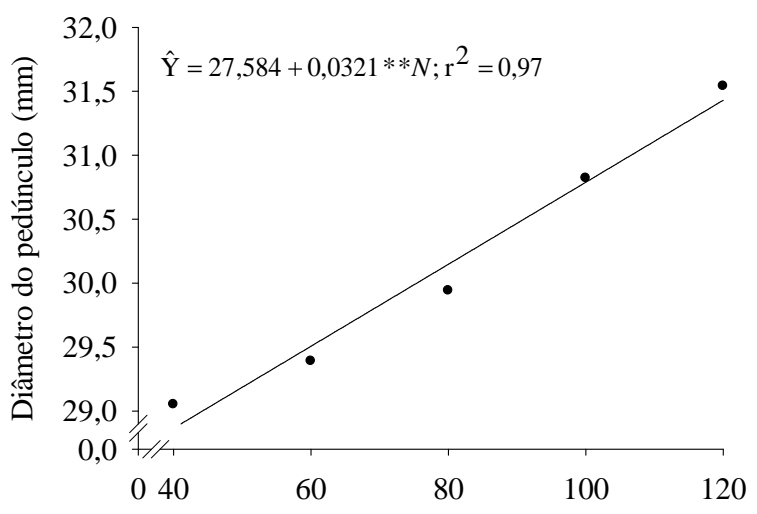

(C)

Dose de nitrogênio $\left(\mathrm{kg} \mathrm{ha}^{-1}\right)$

Figura 1 - Representação gráfica das características: (A) Acamamento de plantas da cultivar Pioneiro ${ }^{1}$; (B) Altura das plantas; (C) Diâmetro do pedúnculo; (D) Massa de mil grãos de trigo, em resposta a doses de nitrogênio. ${ }^{1} \mathrm{O}$ gráfico de acamamento de plantas refere-se apenas à cultivar Pioneiro, pois a cultivar BRS 210 não apresentou acamamento. Os demais gráficos referem-se à média das duas cultivares, pois não houve efeitos significativos das interações. 
característica pode resultar em decréscimo de outra, assim o aumento linear do número de grãos por espiga (Figura 2), pode ter aumentado a competição por fotoassimilados e contribuído para menor massa de grãos.

O número de grãos por espiga, número de espigas por $\mathrm{m}^{2}$ e a massa seca da parte aérea das plantas de trigo aumentaram linearmente com as doses de N. A produtividade dos grãos respondeu de forma quadrática, com ponto de máxima em $5.032 \mathrm{~kg} \mathrm{ha}^{-1}$, estimado na dose de $96,8 \mathrm{~kg} \mathrm{ha}^{-1}$ (Figura 2).

Para o número de grãos por espiga, o resultado diferiu do relatado em aveia-preta (Nakagawa et al., 2000), em que não houve diferenças entre as doses estudadas, para a característica número de sementes por panícula do colmo principal. Por outro lado, Buzetti et al. (2006), trabalhando com arroz, encontraram aumentos lineares para a característica número de espiguetas por panícula. Para os efeitos das doses de $\mathrm{N}$ no número de espigas por $\mathrm{m}^{2}$, Mauad et al. (2003) também encontraram diferença significativa, em arroz, quando aplicaram $75 \mathrm{~kg} \mathrm{ha}^{-1}$ de N em relação a não aplicação do nutriente. Isso acontece porque as maiores doses de $\mathrm{N}$ promovem maior vigor vegetativo, principalmente nas fases de perfilhamento e diferenciação do meristema reprodutivo, o que resulta em maiores valores para esses componentes de produção.

Para a massa seca da parte aérea, acréscimos nos valores, em função das doses de $\mathrm{N}$, também foram encontrados na cultivar de trigo EMBRAPA-22, em dois anos de cultivo (Coelho et al., 1998). Esses resultados

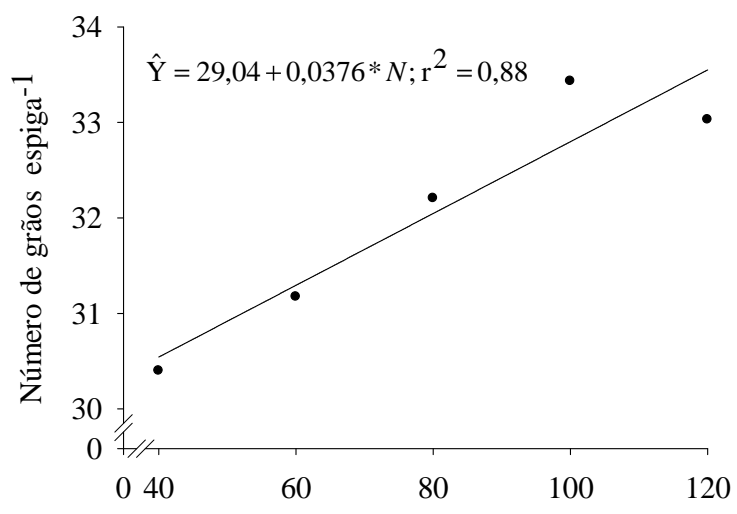

(A)

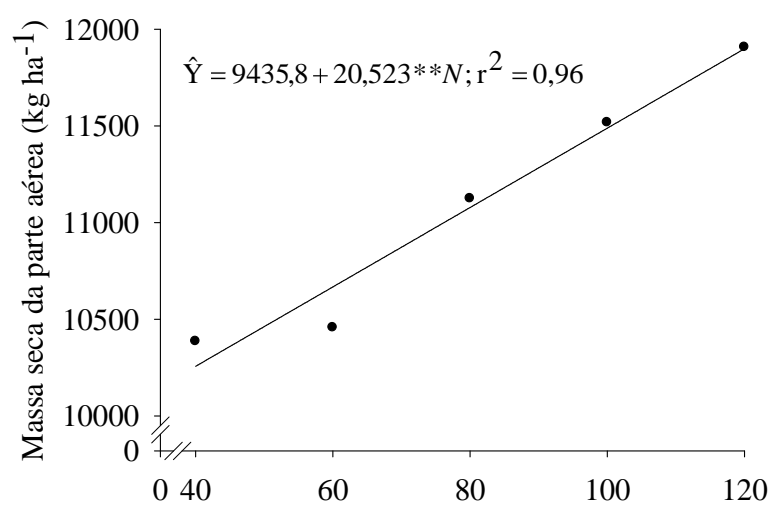

(C)
Dose de nitrogênio $\left(\mathrm{kg} \mathrm{ha}^{-1}\right)$

Dose de nitrogênio $\left(\mathrm{kg} \mathrm{ha}^{-1}\right)$

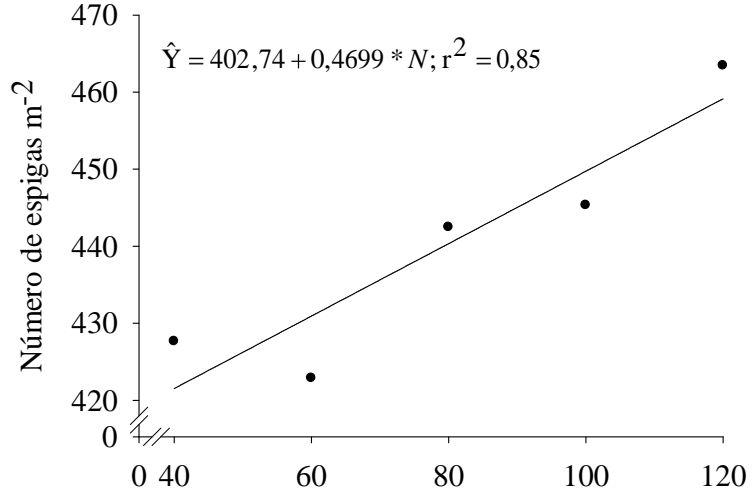

(B)

Dose de nitrogênio $\left(\mathrm{kg} \mathrm{ha}^{-1}\right)$

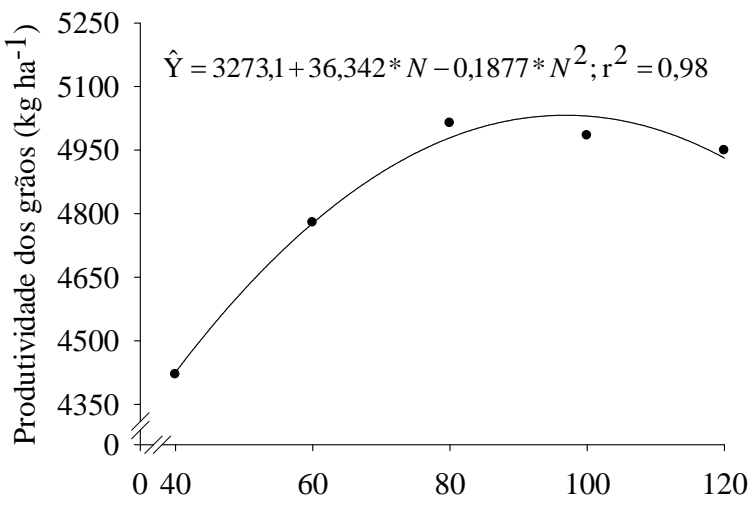

(D)

Figura 2 - Representação gráfica das características: (A) Número de grãos por espiga; (B) Número de espigas por m²; (C) Massa seca da parte aérea; (D) Produtividade de grãos de trigo em resposta a doses de nitrogênio. As curvas referem-se às médias as cultivares e das formas de aplicação, pois as interações não apresentaram efeitos significativos. 
são geralmente esperados, uma vez que o nitrogênio contribui para o crescimento vegetativo das plantas, atuando nas taxas de iniciação e expansão foliar, no tamanho final das folhas e no alongamento do caule (Schröder et al., 2000).

A resposta quadrática para produtividade concorda com os relatados para trigo (Coelho et al., 1998; Teixeira Filho et al., 2007; Espindula et al., 2009), arroz (Buzetti et al., 2006) e painço (Soratto et al., 2007). Essa resposta pode ser devido à limitação genética da cultivar BRS 210 e ao acamamento das plantas da cultivar Pioneiro, uma vez que, ao acamarem precocemente ocorrem prejuízos no enchimento de grãos, devido ao bloqueio dos fluxos dos vasos condutores e às menores taxas fotossintéticas da planta. É importante destacar que a redução na produtividade poderia ter sido mais pronunciada se a colheita fosse mecanizada, na qual as plantas acamadas não são colhidas.

\section{CONCLUSÕES}

A cultivar Pioneiro apresenta maior potencial produtivo que a BRS 210 , porém apresenta também menor resistência ao acamamento.

O parcelamento da adubação nitrogenada proporciona maior acamamento, na cultivar Pioneiro e não traz benefícios à produtividade dos grãos.

As doses de $\mathrm{N}$ promovem resposta quadrática da produtividade dos grãos, com ponto de máxima de $5.032 \mathrm{~kg} \mathrm{ha}^{-1}$, estimado na dose de $96,8 \mathrm{~kg} \mathrm{ha}^{-1}$, e aumento linear do acamamento de plantas da cultivar Pioneiro.

\section{AGRADECIMENTOS}

Ao "Conselho Nacional de Desenvolvimento Científico e Tecnológico" (CNPq) e a "Fundação de Amparo à Pesquisa do Estado de Minas Gerais" (FAPEMIG), pelas bolsas e auxílios concedidos.

\section{REFERÊNCIAS BIBLIOGRÁFICAS}

ALVAREZ, R.C.F.; CRUSCIOL, C.A.C.; TRIVELIN, P.C.O.; RODRIGUES, J.D.; ALVAREZ, A.C.C. Influencia do etil-trinexapac no acúmulo, na distribuição de nitrogênio $\left({ }^{15} \mathrm{~N}\right)$ e na massa de grãos de arroz de terras altas. Revista Brasileira de Ciência do Solo, Viçosa, v.31, n.6, p.1487-1496, 2007.

BREDEMEIER, C.; MUNDSTOCK, C.M. Estádios fenológicos do trigo para a adubação nitrogenada em cobertura. Revista Brasileira de Ciência do Solo, Viçosa, v.25, n.2, p.317-323, 2001.
BUZETTI, S.; BAZANINI, G.C.; FREITAS, J.G.; ANDREOTTI, M.; ARF, O.; SÁ, E.; MEIRA, F.A. Resposta de cultivares de arroz a doses de nitrogênio e do regulador de crescimento cloreto de clormequat.

Pesquisa Agropecuária Brasileira, Brasília, v.41, p.17311737, 2006.

CANTARELLA, H. Nitrogênio. In: NOVAIS, R.F.; ALVAREZ,V.H.; BARROS, N.F.; FONTES, R.L.F.; CANTARUTTI, R.B.; NEVES, J.C.L. Fertilidade do solo. Viçosa, MG: Sociedade Brasileira de Ciência do Solo, 2007.

COELHO, M.A.O.; SEDIYAMA, T.; SOUZA, M.A.; RIBEIRO, A.C.; SEDIYAMA, C.S. Composição mineral e exportação de nutrientes pelos grãos do trigo irrigado e submetido a doses crescentes e parceladas de adubo nitrogenado. Revista Ceres, Viçosa, v.48, p.81-94, 2001.

COELHO, M.A.O.; SOUZA, M.A.; SEDIYAMA, T.; RIBEIRO, A.C.; SEDIYAMA, C.S. Resposta da produtividade de grãos e outras características agronômicas do trigo EMBRAPA-22 irrigado ao nitrogênio em cobertura. Revista Brasileira de Ciência do Solo, Viçosa, v.22, p.555-561, 1998.

DATE, R.A. Inoculated legumes in cropping systems of the tropics. Field Crops Research, Amsterdam, v.65, p.123-136, 2000.

EMPRESA BRASILEIRA DE PESQUISA AGROPECUÁRIA. Informações técnicas para a cultura de trigo na Região do Brasil Central: safra 2005 e 2006. Goiânia, 2004. 82p. (Documentos, 173).

ESPINDULA, M.C.; ROCHA, V.S.; FONTES, P.C.R.; SILVA, R.C.C.; SOUZA, L.T. Effect of nitrogen and trinexapac-ethyl rates on the spad index of wheat leaves. Journal of Plant Nutrition, Philadelphia, v.32, n.11, p.1956-1964, 2009.

FONTES, J.R.M.; CARDOSO, A.A.; SOUZA, M.A.; CRUZ, C.D. Relação do espaçamento e da densidade de semeadura com o rendimento de grãos e outras características agronômicas do trigo. Revista Ceres, Viçosa, v.47, p.61-73, 2000.

GRAHAM, P.H.; VANCE, C.P. Nitrogen fixation in perspective: an overview of research and extension needs. Field Crops Research, Amsterdam, v.65, p.93-106, 2000 . 
MAUAD, M.; CRUSCIOL, C.A.C.; GRASSI FILHO, H.; CORRÊA, J.C. Nitrogen and silicon fertilization of upland rice. Scientia Agrícola, Piracicaba, v.60, p.761765, 2003.

MEGDA, M.M.; BUZETTI, S.; ANDREOTTI, M.; TEIXEIRA FILHO, M.M.C.; VIEIRA, M.X. Resposta de cultivares de trigo ao nitrogênio em relação às fontes e épocas de aplicação sob plantio direto e irrigação por aspersão. Ciência e Agrotecnologia, Lavras, v.33, n.4, p.1055-1060, jul./ago., 2009.

NAKAGAWA, J.; CAVARINI, C.; MACHADO, J.R. Adubação nitrogenada no perfilhamento da aveia-preta em duas condições de fertilidade do solo. Pesquisa Agropecuária Brasileira, Brasília, v.35, p.1071-1080, 2000.

PÖTTKER, D.; ROMAN, E.S. Efeito do nitrogênio em trigo cultivado após diferentes sucessões de culturas. Pesquisa Agropecuária Brasileira, Brasília, v.33, p.501507, 1998.

RAMBO, L.; SILVA, P.R.F. da; ARGENTA, G.; SANGOI, L. Parâmetros de planta para aprimorar o manejo da adubação nitrogenada de cobertura em milho. Ciência Rural, Santa Maria, v.34, p.1637-1645, 2004.

SANGOI, L.; BERNS, A.C.; ALMEIDA, M.L.; ZANIN, C.G.; SCHWEITZER, C. Características agronômicas de cultivares de trigo em resposta à época da adubação nitrogenada de cobertura. Ciência Rural, Santa Maria, v.37, n.6, p.1564-1570, 2007.

SCHRÖDER, J.J.; NEETESON, J.J.; OENEMA, O.; STRUIK, P.C. Does the crop or the soil indicate how to save nitrogen in maize production?: Reviewing the state of the art. Field Crops Research, Amsterdam, v.66, p.151-164, 2000.
SIMILI, F.F.; REIS, R.A.; FURLAN, B.N.; PAZ, C.C.P.; LIMA, M.L.P.; BELLINGIERI, P.A. Resposta do híbrido de sorgosudão à adubação nitrogenada e potássica: composição química e digestibilidade in vitro da matéria orgânica. Ciência e Agrotecnologia, Lavras, v.32, n.2, p.474-480, 2008.

SORATTO, R.P.; CARDOSO, S.M.; SILVA, Â.H.; COSTA, T.A.M.; PEREIRA, M.; CARVALHO, L.A. Doses e épocas de aplicação de nitrogênio em cobertura na cultura do painço (Panicum miliaceum L.). Ciência e Agrotecnologia, Lavras, v.31, n.6, p.1661-1667, 2007.

TEIXEIRA FILHO, M.C.M.; BUZETTI, S.; ALVAREZ, R.C.F.; FREITAS, J.G.; ARF, O.; SÁ, M.E. Resposta de cultivares de trigo irrigados por aspersão ao nitrogênio em cobertura na região do Cerrado. Acta Scientiarum Agronomy, Maringá, v.29, n.3, p.421-425, 2007.

TRINDADE, M.G.; STONE, L.F.; HEINEMANN, B.; CÁNOVAS, A.D.; MOREIRA, J.A.A. Nitrogênio e água como fatores de produtividade do trigo no cerrado.

Revista Brasileira de Engenharia agrícola e Ambiental, Campina Grande, v.10, p.24-29, 2006.

VIEIRA, R.D.; FORNASIERI-FILHO, D.; MINOHARA, L.; BERGAMASCHI, M.C.M. Efeito de doses e de épocas de aplicação de nitrogênio em cobertura na produção e qualidade fisiológica de sementes de trigo. Científica, São Paulo, v.23, n.2, p.257-264, 1995.

WAMSER, A.F.; MUNDSTOCK, C.M. Adubação nitrogenada em estádios fenológicos em cevada, cultivar "MN 698". Ciência Rural, Santa Maria, v.37, n.4, p.942948, 2007.

ZAGONEL, J.; FERNANDES, E.C. Doses e épocas de aplicação do regulador de crescimento afetando cultivares de trigo em duas doses de nitrogênio. Planta Daninha, Viçosa, v.25, n.2, p.331-339, 2007. 